\title{
LA ESCRITORA Y EL HOMBRE-MUSA (CARMEN MARTÍN GAITE EN EL CUARTO DE ATRÁS)
}

\section{Raquel Gutiérrez Estupiñán}

Universidad Autónoma de Puebla, México

El Premio Nadal 1957 que Carmen Martín Gaite (CMG) gana por su novela Entre visillos no fue el primero en su carrera literaria: tres años antes (en 1954) se había hecho acreedora al Premio Gijón por El balneario. Estas obras significan las bases de una producción que ha continuado su fluir ininterrumpido, jalonado aquí y allá por reconocimientos como el Premio Nacional de Literatura 1978 (año en que se publica El cuarto de atrás); el premio Príncipe de Asturias vino diez años después, para seguir luego con el Premio Anagrama (por el ensayo Usos amorosos de la postguerra española), y el Premio Nacional de las Letras en 1994.

CMG pertenecería, dentro de la historia de la literatura española, a los escritores de la generación del medio siglo, al lado de escritores nacidos después de 1920 y que publican primeras novelas hacia los años cincuenta, como Ignacio Aldecoa y Jesús Fernández Santos (1954), Rafael Sánchez Ferlosio (1951), Ana María Matute (1948), entre otros (Martínez Cachero, 1980: 333). 
Sin embargo la obra de CMG no puede encasillarse dentro de una sola década. Y de hecho, lo que nos interesa destacar aquí es una novela de los años setenta, El cuarto de atrás, que participa del carácter de ruptura que marcó la producción novelística de esa época (Sobejano, 1980: 500) y cuyos rasgos sobresalientes - memoria, escritura y fantasía - están bien representados en este texto. Dichos rasgos, no exclusivos de las novelas de CMG, se hallan en su caso matizados por el hecho de tratarse de una escritora y no de un escritor (ni siquiera en el sentido «neutro» o «universal» en el que comúnmente se pretende englobar a quienes escriben).

La anécdota propiamente dicha de $E l$ cuarto de atrás se reduce a que en una noche de tormenta, la escritora-protagonista-Carmen recibe la visita de un hombre misterioso que dice haber concertado una cita para entrevistarla, aunque ni el desarrollo de la novela ni el desenlace dejen claro que ése era el verdadero objeto de la visita. Lo que da forma a la novela es la madeja de recuerdos que la escritora va desenredando mediante el diálogo con el hombre de negro. A través de esas evocaciones del pasado Carmen reconstruye los últimos años de su infancia sumergida en el franquismo; el «cuarto de atrás» aparece con nitidez como una metáfora de la vida femenina interior, del lugar donde se guarda aquello que nos toca muy de cerca. Metáfora, también, del desorden feliz que le da a la protagonista la sensación de estar segura, y plataforma desde donde se proyectan las fantasías de la casi adolescente Carmen, concretadas en lugares como Cúnigan y Bergai.

En el entramado de la novela intervienen también numerosas alusiones a la escritura y fragmentos de autocrítica, todo lo cual se entreteje estrechamente con el material autobiográfico en que se sustenta la narración. El desenlace de la novela es el final de la fantasía y de la escritura de El cuarto de atrás y viene señalado por la irrupción de la hija de Carmen, quien regresa luego de pasar la noche con unos amigos. La alusión a la tormenta y a ciertos vestigios de la visita (dos vasos en la sala, la cajita dorada) prolongan la duda acerca de la presencia efectiva del misterioso hombre de negro en el departamento de Carmen.

Un rasgo que llama la atención en El cuarto de atrás es el diálogo que, una vez entablado entre la escritora y el hombre de negro, se constituye en el principal elemento de cohesión de los otros componentes de la novela. En uno de los estudios que consagra a la literatura española escrita por mujeres en su libro Desde la ventana, CMG reflexiona sobre el papel de Rosalía de Castro (n. 1837) en la época del Romanticismo, y señala que esta escritora protestó contra el concepto romántico de la musa (siempre mujer) como molde vacío (Martín Gaite, 1987: 90). Conviene aclarar que la descripción de la mujer musa en el siglo XIX que realiza CMG está enmarcada en una serie de reflexiones sobre el Romanticismo en España. Para contrastar los rasgos 
típicos de la musa hace hincapié en el narcisismo del Bécquer de las Rimas o de Espronceda en el Canto a Teresa, poetas perseguidores de mujeres en las que hacían encarnar el ideal del ente abstracto motor de la inspiración. Por el contrario, el hombre-musa de Rosalía de Castro no se limita a la repetición de rasgos en clave masculina, sino que los transforma para crear un ser que responda a un tipo de necesidad distinto al que buscaban los poetas del XIX. Si acaso subsiste un rasgo de la musa tradicional, es el misterio, pero derivado de lo fantástico, no de una naturaleza masculina «inefable».

La extraña novela de Rosalía de Castro que lleva por título El caballero de las botas azules comienza con una especie de prólogo en el que una musa -interlocutora del poeta arrogante - le promete que lo hará circular en la sociedad madrileña bajo la figura de «un héroe de nuestros tiempos» para que represente «la más aplaudida, ridícula y singular comedia» del siglo (1973: 43). Provisto de unas singulares botas ${ }^{1}$ y de un aguilucho «ostentándose misterioso y simbólico sobre su pecho» (1973: 114), entrará en contacto con varias damas de la sociedad madrileña del siglo XIX y —aquí reside lo singular, percibido agudamente por CMG- se convertirá en interlocutor de cada una de ellas ${ }^{2}$, otorgándoles con toda naturalidad la ocasión de hablar con él, y de ser escuchadas.

Al leer este capítulo de Desde la ventana se hace evidente la fascinación que sintió CMG por el personaje de El caballero de las botas azules, y es lo que nos ha llevado a postular esta novela de Rosalía de Castro como intertexto primordial para El cuarto de atrás ${ }^{3}$. En efecto, el hombre de negro en la novela de CMG desempeña una función muy semejante a la del caballero de las botas azules en la novela de la escritora del siglo XIX, sólo que todo aquello que estaba planteado como programa en la obra de Rosalía de Castro se presenta como realización en la de CMG. Podemos darnos cuenta de la impresión provocada por el héroe de la novela de Castro en la siguiente cita de Desde la ventana:

Es muy interesante [...] la noción del hombre como acicate no sólo amoroso, sino también intelectual de la mujer [...] y que podría interpretarse como transposición

1 Las cuales despiden un «brillantísimo, maravilloso resplandor» y son «azules como el cielo, encanto de las mujeres, tormento de los zapateros y asombro de los sabios» (Castro, 1973: 114).

${ }^{2}$ Las mujeres pertenecen a distintas clases sociales, desde la jovencita de barrio pobre (Dorotea), las mujeres «de alta sociedad» (como la señora Vinca-Rúa o la duquesa de Pampa) hasta la singular Casimira, la «mujer fuerte», de la que hablaremos más adelante.

3 Entendemos por intertexto un texto A (anterior) presente en un texto B, de tal modo que se hallen en una relación de evocación consciente o inconsciente, más o menos explícita, parcial o total, con renovación o transformación creativa del texto A en el texto B (definición establecida con ayuda del Diccionario de Retórica y Poética de Helena Beristáin). 
del concepto de musa, simbolizada por una joven pálida y de mirada ausente, al del hombre desconocido e inquietante como motor que espolea la imaginación femenina, disparándola hacia horizontes más amplios. Esta noción de hombremusa, propuesta como ideal femenino de superación, está tan presente en El caballero de las botas azules que puede decirse que constituye su argumento (pp. 95-96; subrayado nuestro).

Además del concepto de hombre-musa esbozado en las líneas anteriores, es sumamente atractiva, en la misma novela, la noción de la amistad como algo más peligroso que el amor, la «tentación diabólica de una amistad con el sexo contrario» (Martín Gaite, 1987: 96-97). En El caballero de las botas azules esta noción aparece ampliamente desarrollada en el capítulo XI, a través del diálogo que sostiene el protagonista (también llamado el duque de la Gloria) con Casimira. Nuestra idea es que toda la construcción de El cuarto de atrás se halla esquematizada aquí, incluso en el hecho de que la presencia del hombre está enmarcada por su llegada y su partida, y en que la conversación se lleva a cabo en un lugar bien determinado y "perteneciente» a la esfera de la mujer (habitación y jardín en El caballero de las botas azules; sala del departamento de Carmen en El cuarto de atrás), que asume una importante función semiótica en ambos casos. Lo que Casimira ambiciona en la relación con el duque de la Gloria es la amistad («el que yo ambicionaba tener por mi mejor amigo» p. 166), que considera como un terreno en el que se puede llegar más lejos que en el del amor (p. 170); quiere ser para el caballero «inviolable, franca, amiga verdadera»; que él halle en ella cualidades que las mujeres no suelen poseer» (p. 171) ${ }^{4}$. Pretender establecer una relación amistosa entre seres de distinto género sexual equivale a «seguir un camino opuesto al de los demás» (p. 169), lo cual reviste una peligrosidad de la que tanto el caballero como Casimira son conscientes. El caballero afirma en efecto que «La amistad es un sentimiento más grave que el amor, y más comprometido [...]» (p. 173), de ahí que se pueda adivinar el atractivo que ejerce en los participantes, ambos seres de inteligencia y sensibilidad poco comunes.

En El cuarto de atrás la protagonista pone en práctica el programa esbozado en El caballero de las botas azules. Carmen no tiene que insistir en la necesidad (o en el deseo) de constituirse como amiga y confidente del hombre. Cuando el misterioso visitante llega a su departamento, ya es alguien que está preparado para su papel de interlocutor de la escritora, es decir, para interactuar con ella en una situación de diálogo. Carmen hace explícita esta función cuando, al inicio de la conversación con el hombre de negro, leemos:

4 Otras alusiones a la amistad pueden verse en las pp. 168, 171, 172, 174, 175 y 177 de la edición que hemos seguido. 
Cierro los ojos, invadida por una repentina languidez. Así, con los ojos cerrados, me puedo figurar que es un amigo de toda la vida, alguien a quien reencuentro después de una larga ausencia (p. 38) ${ }^{5}$.

En distintos momentos de la velada, Carmen trata de ir configurando en su mente una imagen precisa de su supuesto entrevistador. Cuando llega a figurárselo como tal, lo percibe como a alguien que no se ha conducido como se esperaría que lo hiciera una persona «del oficio»: ni grabadora, ni magnetófono, ni preguntas típicas,

[...] así que me da pie para que le pague en la misma moneda: tampoco mis respuestas tienen por qué ser convencionales (p. 65).

Este proceso de ir construyendo la figura del interlocutor se da igualmente en cuanto a los datos que nos permitirían responder a la pregunta ¿cómo es? ¿qué aspecto tiene el misterioso visitante? Nos detendremos a examinar este punto primero en la novela de Rosalía de Castro, en la cual la lectora/el lector se encuentra ante varias descripciones - bastante parecidas entre sí- del caballero que recorre los salones de Madrid. En resumen, se trata de un hombre joven, elegante, de modales distinguidos, alto y delgado, de semblante blanco, crespa y revuelta cabellera negra, mirada penetrante. Con frecuencia hace gala de una fina ironía y puede asumir un papel claramente directivo y ser «adusto y severo como el mismo Catón» (p. 171). Se otorga mucha importancia a su vestimenta, sobre todo a las fabulosas botas azules; además de aparecerse de pronto, como un duende, se considera que «más bien que un hombre, era una hermosa visión» (p. 97), o una especie de fantasma.

Este carácter misterioso reaparece en el hombre de negro quien, como se recordará, se presenta como salido de la nada en el departamento de Carmen, una noche de tormenta, y que desaparece de la misma manera en que llegó, no sin dejar indicios seguros de su paso por la vida de la escritora. El hombre de negro también es alto («le llego por el hombro», anota Carmen, p. 100), algo encorvado, de manos expresivas y ojos intensamente brillantes; su voz tiene un tono seguro y sus modales son desenvueltos. En cuanto a su ropa, sólo se indica que viste de negro, con un sombrero «de grandes alas» del mismo color.

Interesa igualmente llamar la atención sobre cómo aparecen los personajes femeninos. Casimira se presenta como una mujer hermosa, hechicera, «alta y

5 Los números de las páginas después de las citas corresponden a las ediciones de las novelas de Rosalía de Castro y Carmen Martín Gaite indicadas en la bibliografía. 
un tanto varonil» (p. 165), de gran talento y fortuna. A pesar de que no se trata ya del estereotipo de la mujer angelical del Romanticismo, todavía se perciben rasgos convencionales, que ya no se encuentran en la protagonista de El cuarto de atrás. Carmen, en efecto, es una mujer de más de cincuenta años, un poco sorda; eso sí - y se trata de un rasgo del que evidentemente es consciente y le hace sentirse orgullosa - muy talentosa y dueña de su oficio de escritora. Por una parte, se sigue percibiendo como mujer frente al entrevistador, pero esto se da en la novela por medio de la autopercepción, indicada por las numerosas alusiones a la proximidad física con el hombre de negro ${ }^{6}$; no podía ser de otro modo, tratándose de una novela en primera persona (con narradora intra y homodiegética), y esto la sitúa dentro de las tendencias de la novela española de los años setenta. En cierto modo, pues, Carmen es la anti-belleza; desde una perspectiva tradicional podría dar la impresión de haber «perdido» cualidades femeninas debido, sobre todo, a su edad. Sin embargo la escritura tiende a presentar una figura femenina auténtica, sin recurso a falsas apariencias, tal como es al paso de los años, que sigue siendo femenina tanto en su comportamiento y autopercepción frente al hombre, como por su naturaleza de escritora.

A partir de la presencia física del hombre se construye este como «hombre-musa». En la novela de CMG encontramos, una vez más, que la escritura le da otras dimensiones a los rasgos que ha intuido - más que leído- en el personaje de El caballero de las botas azules, donde aparece el hombre como interlocutor de las mujeres, propiciando que hablen de sí mismas pero sin representar un estímulo para ningún tipo de creación.

Desde el principio de la entrevista, cuando Carmen conduce al hombre de negro hacia el salón, y se detiene a explicarle el susto que ha pasado unos minutos antes al ver en el pasillo una enorme cucaracha, observa que en la actitud de su visitante «no se [le] trasluce ánimo de fiscalizar sino de esclarecer, de aportar ayuda» (p. 36). En otro momento Carmen analiza que aquello que el hombre de negro le inspira no es confianza, sino algo «inquietante y sugestivo, como una continua incitación a mentir» (p. 97). Es el mismo sentimiento de atracción ante el peligro de internarse en una relación «diferente» que encontramos entre Casimira y el caballero de las botas azules. Se percibe, además, el mismo tono de fascinación por este tipo de hombre al hacer su comentario sobre el hombre-musa en Rosalía de Castro (vide supra).

Conforme asume su papel de acicate de la intelectualidad de Carmen, el visitante la animará a «fugarse». Cuando la escritora le pide que perdone sus

6 Sólo algunos ejemplos: «Yo me incorporo automáticamente y me corro hacia el rincón; habíamos quedado demasiado juntos» (p. 33); «nuestros dedos se rozan» (p. 99); «nuestros ojos se encuentran» (p. 140); «siento su pecho latiendo contra el mío [...]. Hundo la cabeza en su hombro» (p. 199). 
continuas escapadas durante la conversación («las fugas siempre merecían severo castigo», p. 122), él le dice con «dulzura turbadora»:

-Me gustan mucho sus fugas [...]. Por mífúguese todo lo que quiera, lo hace muy bien (p. 122).

Carmen se sorprenderá por esta reacción: «Me ha dicho que soy una fugada, me lo ha dicho sin reproche alguno» (p. 123), y esto la halaga y la inquieta a la vez.

A medida que avanza el diálogo, Carmen reconoce plenamente la función inspiradora del hombre de negro, como cuando se dice a sí misma:

La conversación con este hombre me ha estimulado y refrescado mi viejo tema de los usos amorosos de postguerra (p. 73).

¿Habría un ejemplo más claro de la función que asume el hombre como inspirador de la creación literaria en una mujer? Carmen, la escritora, ha hecho encarnar su inspiración. Los hombres habían recurrido desde siempre a las musas; ella propone una alternativa propia de las mujeres, y ésta asume rasgos masculinos. Esta masculinidad estimulante estaba ya en germen en $E l$ caballero de las botas azules y aparece aquí diestramente adaptada al momento en que CMG escribe y crea. Un pasaje que resume este papel del hombre de negro es el siguiente:

\footnotetext{
Ahora ya he comprendido claramente que no tiene prisa ni lleva programa ni se esfuerza por agotar temas, todo queda insinuado, esbozado, como en una danza cuyos pasos vamos ensayando juntos, a golpe de improvisación. Tenemos mucha noche por delante, un espacio abierto, plagado de posibilidades [...] (p. 106).
}

Estos rasgos de no convencionalidad, de carecer de programa rígido previo; este carácter de esbozo y de improvisación parecen definir la escritura de las mujeres, tal como la han descrito muchas autoras. El espacio abierto es el de la libertad para crear, espacio que cada escritora se ha construido de diferentes maneras a lo largo de la historia de la escritura femenina.

Ahora bien, todos los elementos anteriores se relacionan estrechamente con la función del hombre como provocador de la memoria. A determinada altura de la velada, el hombre de negro saca de su bolsillo una cajita dorada 
que contiene diminutas pastillas de colores; le ofrece a Carmen probar una, explicándole que son para la memoria:

- -Ah!... ¿Avivan la memoria?

Bueno, sí, la avivan, pero también la desordenan, algo muy agradable (pp. 107108).

Se ve aquí que los rasgos del visitante no son los de los hombres comunes, de quienes se ha dicho que tienden - aun en la escritura - a buscar el orden, a imponer reglas, a remitirse a textos canónicos, autoritarios. En cambio el hombre de negro estimula el desorden tan necesario para el trabajo creativo de Carmen; llegará a decirle que «el desorden en que surgen los recuerdos es su única garantía $[. .] ».($ p. 116) 7 .

En cuanto a la relación de los interlocutores en el capítulo XI de la novela de Rosalía de Castro, ya hemos visto que Casimira no desea establecer una relación amorosa con el caballero. Aquí insistiremos en que ambos son conscientes de involucrarse en una situación de diálogo, lo cual queda claro por la abundancia de indicadores como «hablaremos ahora con calma» (p. 167), «discutamos lo que casi siempre es indiscutible entre dos seres simpáticos» (p. 169), «prosigamos [...] nuestra [...] conversación» (p. 171), etc. ${ }^{8}$. Lo que caracteriza en última instancia este diálogo es que no se prolonga por mucho tiempo, no se establece finalmente ninguna relación, porque Casimira, con todo su ingenio y su hermosura, no puede conmover «el carácter de hierro del duque» (p. 178).

La conversación llega a ser percibida como un combate en el que aparentemente la mujer sale vencida, pero de donde el duque tampoco sale incólume. El hecho de que haya vencedor y vencida se debe, en gran parte, a que Casimira se plantea la relación con el duque como «un reto». Curiosamente, hay un momento en El cuarto de atrás en el que la escritora experimenta la misma sensación si no de derrota, sí de hallarse en situación de desventaja. A la observación del hombre de negro de que «hay que elegir entre perderse [en un laberinto] o defenderse [en un castillo]», Carmen decide no replicar porque él sabe más esgrima que ella; el sombrero negro se halla sobre la

$7 \mathrm{El}$ concepto de «desorden» debe entenderse —en esta novela y en muchas escritas por mujeres - en el sentido positivo de ambiente propicio para el trabajo intelectual que se desarrolla sin ataduras. En El cuarto de atrás son abundantes las alusiones que conectan el desorden con la irregularidad, la desobediencia, la transgresión del umbral, la locura (en el sentido que le dan G. Gilbert y S. Gubar en The Madwoman in the Attic).

8 Recordemos que en esta situación de diálogo se mantiene el carácter sexuado de los participantes en las dos novelas. 
mesa «como una especie de pájaro de las tormentas celebrando mi derrota» (p. 56).

También en El cuarto de atrás hay una voluntad de diálogo muy clara, con marcas que pueden resumirse en el «Sígame contando» del hombre de negro (p. 108). La escritura recurre profusamente al diálogo; véase el siguiente ejemplo, que muestra cómo es precisamente este elemento dialógico el que engarza los demás que constituyen la novela:

- ¿Es un artículo suyo? - pregunta el hombre.

$-S i$, trata precisamente de eso, ¿quiere usted que se lo lea?

- Me gusta más oírla hablar, pero bueno.

-Es que leérselo me puede dar sugerencias, y como ahora estoy en un momento de entusiasmo.

-iAh, si, eh!

-Sí, estoy segura de que si me sentara a la máquina me pondría a escribir de corrido.

-Si quiere, me voy.

-No, por favor, es estando usted aquí como se me ocurren las cosas.

Pues si le parece, me siento ahí en el suelo, a su espalda y usted se pone a escribir.

- No estaría mal.

Pero tendría que aprender a escribir como habla.

-Ya lo creo, no ha dicho usted nada. Es lo más dificil que hay.

-Bueno, a ver, léame el artículo [...] (pp. 138-139).

A pesar de que es un ejemplo, entre muchos posibles, se puede apreciar el funcionamiento del dialogismo en el sentido bajtiniano de coexistencia de dos voces que influyen una en otra, sin que ninguna domine, y donde se entrecruzan no sólo palabras, sino también experiencias y visiones del mundo ${ }^{9}$.

De acuerdo con Sobejano (1980), uno de los factores de ruptura presentes en la novela española de los años setenta es el diálogo entre dos interlocutores no idénticos, de los cuales uno puede poseer rasgos que lo hacen enigmático y misterioso, o fantasmal. Es precisamente el caso en El cuarto de atrás, donde el hombre de negro posee una identidad difusa: su aparición desde el corazón de la tormenta, y su partida sigilosa mientras Carmen se recuesta en el sofá para dormir, la falta absoluta de datos sobre su existencia fuera de esa situación de diálogo ${ }^{10}$, hacen que en cierto momento

9 Se aprecian igualmente rasgos de la función motivadora de creación del hombre de negro.

$10 \mathrm{La}$ voz de Carola, que (en el capítulo V) llama para preguntar por Alejandro, no hace sino complicar aún más el continuo transitar entre la realidad y la fantasía. De hecho, no es seguro que el hombre por el que pregunta Carola (y que ella pinta como machista y Barba Azul) sea efectivamente el hombre de negro que espera en la sala de Carmen, ni que las cartas de las que habla la mujer al teléfono hayan sido escritas por Carmen. 
(cuando se dispone a regresar al salón, luego de haber contestado el teléfono) la escritora lo espere todo sobre su aspecto: puede verlo como un prestidigitador, o sentir que

[...] se puede haber convertido en cualquier animal espantoso, en un dragón, en el hombre lobo, puede, incluso, haberse esfumado [...] (p. 167)

Otra de las funciones que asume el diálogo es la de ser una terapia que ayuda a aliviar la tensión entre la protagonista y el entorno social (sobre todo el que evoca con respecto a los años tempranos de su adolescencia) y entre la necesidad de comunicar(se) y las restricciones impuestas por los códigos sociales vigentes. $\mathrm{Al}$ respecto, conviene llamar nuevamente la atención sobre las «fugas» de Carmen. Se trata de lapsos más o menos largos en los que ella se aparta del diálogo con el hombre de negro - aunque el «salto» se dé precisamente a partir de alguna observación o pregunta suya - para internarse, sola, en sus laberintos personales. Estas fugas pueden consistir en analepsis a momentos de la infancia vivida bajo el régimen de Franco, o bien en la invención de lugares para refugiarse del mundo de los adultos y que revelan un intenso anhelo de libertad, de escape. Es el caso de Bergai (la isla que la escritora inventa junto a una amiga suya) y Cúnigan (lugar misterioso surgido de una canción que Carmen no sabe muy bien si escuchó o inventó, p. 79). Pueden ser fugas «hacia atrás, a los orígenes» (p. 135) o bien fugas históricas, inclusive «dobles» (p. 136).

En esta misma línea, un rasgo que $E l$ cuarto de atrás comparte con la novela de su época es que se trasluce la imagen de la autora, quien asume el papel de demiurga, dueña absoluta de las figuras que crea. Así se explican sus intervenciones directas en el mundo imaginado, y el que su discurso narrativo se adapte a los más diversos moldes. En esta novela de CMG esta ambiguiedad aparece en el hecho de que se trata de un texto autobiográfico en el que la identificación personaje-autora puede suponerse explícita al darle el nombre de Carmen a la figura principal; y además del nombre, los apellidos: al revivir una clase de religión, la escritora recuerda que el profesor le llamó la atención diciéndole «Martín Gaite, repita lo último» (p. 145).

La relación dialógica se halla estrechamente interconectada con la memoria, elemento primordial en la composición de El cuarto de atrás, con sus variantes de autobiografía, escritura y autocrítica. Carmen reconstruye la época franquista guiada por las preguntas del hombre de negro («Repaso exhaustivamente mi memoria, como cuando iba, de niña, a confesarme», p. 68). En un contexto sociocultural que ofrecía muy exiguas oportunidades para expresarse, es normal que se haya incrementado la tensión entre el indi- 
viduo y la totalidad, por lo que no es inusual que en los años setenta la escritura se erija como lugar desde donde poner a prueba nuevas posibilidades de expresión, simulacros de libertad, utopías (Sobejamo, 1980: 506). Al rememorar sus años de infancia y adolescencia bajo el régimen de Franco, no es una versión oficial la que Carmen nos presenta, sino una en la que precisamente impera el «desorden» y la confusión (como mecanismo de creación, pero también de autoprotección para el individuo). Carmen procederá a construir $s u$ versión de los años franquistas, recurriendo a un discurso histórico alternativo; la narradora se refiere a esta parte relacionada con el contexto social diciendo que «[...] se me han montado varias imágenes. Yo es que la guerra y la postguerra las recuerdo siempre confundidas» ${ }^{11}$ (p. 127). Varias veces en la novela proporciona datos sobre la guerra y la postguerra: la primera, vista desde los ojos de una niña que no comprendía lo que estaba ocurriendo, y para quien las sirenas que alertaban sobre los bombardeos eran el anuncio de un juego más (p. 60); la segunda, hundida en la mediocridad (p. 52) y marcada por la figura omnipresente de Franco:

Hágase cargo de que yo tenía nueve años cuando empecé a verlo impreso en los periódicos y por las paredes [...] y fueron pasando los años y siempre su efigie y sólo su efigie (p. 133).

Cuando Franco muere por fin, Carmen está a punto de cumplir cincuenta años (faltaban quince días justos); reflexiona sobre el hecho de que -como muchas otras mujeres y muchos otros hombres- ha envejecido «debajo» del generalísimo, percibe su vida enmarcada por un círculo con dos polos (dos mañanas de mucho sol: cuando nació ella y cuando murió Franco, p. 136) y se da cuenta de que de esa época que acaba de terminar ella lo sabía todo, pues lo había venido anotando en un cuaderno (p. 135).

Estas páginas constituyen el momento en que se aprecia claramente cómo la vida colectiva se llega a confundir con la vida de Carmen. Por supuesto que sin redurcirse a los años de Franco, sino trenzando y destrenzando los hechos menudos de su niñez y adolescencia. Al respecto, el cuadro de la era franquista se ve completado con un sinnúmero de datos sobre la vida cotidiana ${ }^{12}$, tales como la costumbre de hacerse permanente, las visitas a la modista en Madrid, la educación de las mujeres, el placer de comerse un

$11 \mathrm{Y}$ en otro lugar: «[...] es una nube gris que se extiende ahora sobre los años de guerra y postguerra, uniformándolos, volviendo imprecisos y opacos los contornos" (p. 107; el subrayado es nuestro).

12 Tema favorito de CMG, y desarrollado admirablemente en Usos amorosos del XVIII en España y Usos amorosos de la postguerra. 
helado, las novelas rosa, Diana Durbin como modelo de belleza, las canciones de Conchita Piquer (que hablaban de pasiones vedadas a las «chicas sensatas y decentes», (p. 154). De modo que también está la parte más personal de los recuerdos de Carmen, aquello que sería lo propiamente autobiográfico y del cual forma parte la escritura, como actividad que propicia la evasión y va de la mano con la fantasía.

El carácter de actividad de la escritura surge al relacionarla con el juego (en particular el de los escondites, p. 191), con la escritura de los primeros diarios guardados en un baúl de hojalata. Más tarde será cuestión de escribir a máquina, de llenar folios ( «Siempre el mismo afán de apuntar cosas que parecen urgentes, siempre garabateando palabras sueltas en papeles sueltos, en cuadernos [...]» (p. 121), hasta llegar a la materialización en los libros. Es en una situación de diálogo donde el hombre de negro vuelve a animar a Carmen para que recuerde:

- ¿A qué edad empezó a escribir? [...]

- ¿Quiere decir a qué edad empecé a refugiarme?

- Sí, eso es lo que he querido decir.

La escritora responderá que empezó a escribir durante la guerra, para refugiarse del frío, «o de los bombardeos» (p. 59); y emprende una nueva fuga. Como proyecto se menciona el libro sobre los usos amorosos de la postguerra, y se da una nueva intervención dialógica del hombre de negro. Habiendo mostrado un vivo interés en la idea de Carmen, le sugiere empezar por el tema de la escasez, que la escritora ya había tocado en un artículo escrito con anterioridad (pp. 178-179). Asimismo, la animará a que escriba aquella «gran historia de amor y misterio que no se atreve a contar» 13 .

Paralelamente se incorporan elementos de autocrítica, sobre todo con respecto a El balneario (1953). Se entabla un diálogo-discusión sobre esta primera novela de CMG que al hombre de negro le parece que prometía mucho, pero luego la escritora tuvo miedo y...

Mediante otra de sus fugas, Carmen retrocede a las fuentes, es decir, a la anécdota que dio origen al libro: unas vacaciones con su familia ${ }^{14}$.

13 «Pues atrévase a contarla [...] Que no sepa si lo que cuenta lo ha vivido o no, que no lo sepa usted misma. Resultaría una gran novela» (p. 197). De nuevo, se ve la función motivadora -y perturbadora- del hombre-musa.

${ }_{14}$ La idea para otra de sus novelas - Ritmo lento, 1963 - surgió una tarde en que, mientras rondaba un viejo chalet, un perro se acercó a la verja y empezó a ladrar (p. 168). Autobiografía, memoria y escritura se entremezclan también en este ejemplo. 
Estas reflexiones sobre el proceso de escribir representarían en la novela de los años setenta la búsqueda del sentido de la existencia en el sentido de la escritura (Sobejano, 1980: 507). En El cuarto de atrás se hace hincapié en que el valor de lo escrito reside en su carácter transitorio, en su estar elaborándose, puesto que «las cosas sólo valen mientras se están haciendo» (p. 129); esta novela que se hace ante los ojos de quien la lee, es una excelente muestra de la idea anterior. Lo que cuenta en efecto es la idea: contar cómo se le ha ocurrido a Carmen escribir su libro «ya es empezar a escribirlo, aunque nunca lo escriba, que eso ¡qué más da!» (p. 129) ${ }^{15}$.

Aun en su soporte material, la escritura posee siempre atributos que la hacen casi cobrar vida: el nombre de Carmen ocupa varios de los renglones ondulantes de una carta, y ella se deja acunar por las líneas rizadas que la llaman como las olas del mar (p. 21); en otro lugar se alude a un cuento «fresco e irregular, tejido de verdades y mentiras, como todos los cuentos», surgido de un intercambio de relatos; aquí la referencia es el carácter oral de la literatura (p. 22). La escritura está presente en todos los rincones del «cuarto de atrás», bajo muy diversas formas, y es el motivo principal de la visita del hombre de negro y de la extensa conversación que sostienen él y la escritora (de ahí las sugerencias, las observaciones, las alusiones a las obras de Carmen - ya escritas o en proyecto-y los rasgos de intertextualidad).

Ligado estrechamente a la escritura, lo fantástico ${ }^{16}$ en El cuarto de atrás es otro componente fundamental, y que además permite detectar otro intertexto de sumo interés. La novela señala desde la dedicatoria a Lewis Carrol y las primeras páginas su filiación con lo misterioso - con frecuencia colocado al lado de la infancia, o de los sueños- y explícitamente con la Introducción a la literatura fantástica de Tzvetan Todorov (1970). Esta obra constituye una especie de marco. Al principio el libro está físicamente ahí, se desploma junto con otros libros cuando Carmen tira de una de las asas del costurero de la abuela Rosario ${ }^{17}$; Carmen enumera algunos de los rasgos que

15 La misma idea aparece cuando, al hablarle al hombre de negro de El balneario, Carmen reflexiona sobre el carácter subversivo de la escritura en una carta escrita para un muchaco que le ha gustado: «[...] ninguna chica modosa de aquel tiempo habría tenido la audacia de escribir una carta así; salí al parque y la estuve releyendo, era totalmente literaria, el destinatario era lo de menos $[\ldots] »($ p. 53).

16 Para Sobejano (1980: 502) es otro de los factores de ruptura en la novela española de los años setenta; «expansividad de la fantasía» que él interpreta como demolición de las barreras que constreñían la mirada del escritor. Cf. también Nichols (1989).

17 Tratándose de una novela escrita por una mujer, esta vecindad entre libros y cosas de costura es muy significativa, y podría leerse como metáfora de la escritura y de la experiencia femeninas: «De la tapadera de mimbre entreabierta escapan carretes, enchufes, terrones de azúcar, dedales, imperdibles, facturas, un cabo de vela, clichés de fotos, botones, monedas, tubos de medicinas, allá va todo, envuelto en hilos de colores» (p. 19). Lo que provoca este «derrame» es precisamente el haber tropezado con el libro de Todorov. 
señala el autor, como el desdoblamiento de la personalidad, la ruptura de límites, la ambigüedad y la incertidumbre. De hecho, la lectura de la Introducción a la literatura fantástica hace que Carmen se prometa a sí misma —y también a Todorov (p. 19)— escribir una novela fantástica. Éste será el proyecto mismo de El cuarto de atrás, que en su desarrollo no se aparta de las ideas de Todorov, y que al final ocupará el lugar que antes ocupaba el libro:

El sitio donde tenía el libro de Todorov está ocupado ahora por un bloque de folios numerados, ciento ochenta y dos. En el primero, en mayúsculas y con rotulador negro, está escrito «El cuarto de atrás». Lo levanto y empiezo a leer: [...] (p. 210).

Lo que empieza a leer Carmen son las primeras líneas de la novela que estamos acabando de leer nosotros.

Carmen y el hombre de negro dialogan sobre la literatura de misterio, de la cual reconocen como clave la ambigüedad: «no saber si aquello que se ha visto es verdad o mentira, no saberlo nunca» (p. 53); a estas alturas está de más decir que ésta es la esencia de la figura del hombre de negro. La clave de la literatura de misterio se halla en la ambigüedad y en la sensación de extrañeza. El visitante ilustra esta idea al hacer notar que en El balneario, cuando la protagonista y el acompañante se apoyan juntos contra la barandilla del puente para mirar el río, en ese momento la escritura logra aprehender la esencia de lo fantástico. Si bien esta sensación se mantiene en la primera parte del relato, en la segunda Carmen «lo echa todo a perder» por no atreverse a seguir avanzando por el camino de los sueños, es decir, por haberse dejado invadir por el temor. En este sentido la escritura de El cuarto de atrás vendría a ser una auto-reivindicación, al proponerse —esta vez sí- lograr una novela fantástica.

Este difuminarse de los límites («cuando lo real y lo ficticio se confunden», p. 17) que se da a todo lo largo de la novela (en las fugas de Carmen, en la confusión provocada por los sueños, en detalles de la velada con el hombre de negro, en la creación de espacios), es evocada mediante la idea del umbral, de una zona donde hay cabida para lo imprevisto, un límite a partir del cual el mundo se vuelve misterioso (p. 87). Lo fantástico se inmiscuye incluso en la vida cotidiana: alrededor de Carmen ciertos objetos mudan de sitio (como el grabado de Lutero), algunas frases son cambiadas, aparecen de pronto setenta y nueve folios, o bien el tanto que ocupan se va engrosando (pp. 99-101).

En este tipo de literatura que se concibe como «un desafío a la lógica» (p. 55), el espacio se proyecta de modo alegórico. Sobejano (1980: 503) da 
como ejemplo de ese vuelo del sujeto que escribe hacia el espacio ilimitado (nosotros añadiríamos: de lo fantástico) el trastero de El cuarto de atrás. Ese cuarto durante la infancia de Carmen era un lugar para salvarse «del agobio de lo práctico». Durante una íntima conversación con su madre, hablando de la casa en donde ella había pasado su infancia, descubren que las dos han tenido su cuarto de atrás, el cual adquiere toda su dimensión simbólica cuando Carmen añade:

[...] me lo imagino también como un desván del cerebro, una especie de recinto secreto lleno de trastos borrosos, separado de las antesalas más limpias y ordenadas de la mente por una cortina que solo se descorre de vez en cuando [...] (p. 91).

Memoria, espacio, fantasía, umbral: volvemos a encontrar todos esos componentes que forman un tejido cerrado, firme, del cual nada puede aislarse sin destruir la pieza. Insistamos, por último, en el hombre de negro, el hombre-musa, como una creación que no deja de tener un carácter subversivo, en el sentido de que al representar una visión alternativa de la figura masculina en relación con la mujer (aquí Carmen, la escritora), abre la posibilidad de modificar radicalmente las imágenes estereotipadas a las que desafortunadamente - por lo empobrecedoras - nos ha acostumbrado una buena parte de la tradición textual y es, por lo tanto, gratificante y liberadora.

\section{Referencias bibliográficas}

CASTRo, Rosalía de (1973). El caballero de las botas azules. Madrid: Editorial del Magisterio Español, S.A. (Col. Novelas y Cuentos, 2. época).

Martín GAITE, Carmen (1987). Desde la ventana. Madrid: Espasa-Calpe (Col. Austral, núm. A 305).

- (1989). El cuarto de atrás. Barcelona: Ediciones Destino (Áncora y Delfín).

Martínez CaChero, J. M. et alii (1980). «La novela». En Rico, Francisco (dir.): Historia y Crítica de la Literatura Española, t. 8, 318-352. Barcelona: Editorial Crítica.

NICHOLS, Geraldine (1989). «Limits Unlimited: The Strategic Use of Fantasy in Contemporary Women's Fiction of Spain». En Cultural and Historical Grounding for Hispanic and Luso-Brazilian Feminist Literary Criticism, Hernán Vidal (ed.). Minneapolis: The Institute for the Study of Ideologies and Literature.

Sobejano, Gonzalo (1980). «Ante la novela de los años setenta». En Rico, Francisco (dir.): Historia y Crítica de la Literatura Española, t. 8, 500-508. Barcelona: Editorial Crítica.

TODOROv, Tzvetan (1970). Introduction à la littérature fantastique. Paris: Seuil (Coll. Points). 